\title{
A new twist to an old tale: novel insights into the differential toxicities of acetaminophen and its regioisomer $N$-acetyl-meta-aminophenol (AMAP)
}

\author{
J. Gerry Kenna
}

Received: 22 August 2012/Accepted: 13 September 2012/Published online: 23 September 2012

(C) Springer-Verlag Berlin Heidelberg 2012

Within the toxicological community, it is generally accepted that, whereas the widely used analgesic and antipyretic drug acetaminophen ( $N$-acetyl-para-aminophenol) causes dose-dependent liver toxicity in humans and in various animal species, its regioisomer $\mathrm{N}$-acetyl-metaaminophenol (AMAP) does not. Liver injury caused by acetaminophen is initiated by cytochrome P450 (CYP)mediated bioactivation to $\mathrm{N}$-acety-para-benzoquinoneimine (NAPQI), which is a chemically reactive intermediate that is formed at high levels following overdosage and triggers a complex cascade of events, which ultimately result in hepatocellular necrosis (Hinson et al. 2010; see Fig. 1). AMAP also undergoes extensive CYP-mediated bioactivation to chemically reactive species in vitro and in vivo (Rashed and Nelson 1989; Rashed et al. 1990; see Fig. 2), yet when AMAP is administered to mice and hamsters in vivo, it has been reported that it does not cause liver injury (Tirmenstein and Nelson 1989; Roberts et al. 1990). Furthermore, studies undertaken in vitro using isolated mouse hepatocytes have revealed that AMAP has a markedly reduced propensity to cause cytotoxicity when compared with acetaminophen, even though AMAP treatment results in higher levels of covalent binding to proteins (Holme et al. 1991). It has been concluded that bioactivation of AMAP to reactive intermediates which form protein adducts does not trigger the critical downstream events by which reactive metabolites of acetaminophen cause liver injury.

The chemical and biochemical basis for this difference in toxicity remains elusive. It is known that acetaminophen

J. G. Kenna $(\square)$

Molecular Toxicology, Global Safety Assessment, AstraZeneca,

Alderley Park, Macclesfield, UK

e-mail: jgerrykenna@gmail.com and AMAP form different reactive intermediates (see Figs. 1,2) and that in the mouse and hamster, glutathione conjugate formation and hepatic glutathione depletion occur to a much greater extent following administration of acetaminophen (Rashed et al. 1990; Roberts et al. 1990). Protein adduct formation occurs more quickly following administration of AMAP to mice than following administration of acetaminophen, and liver protein adducts derived from AMAP are less long lived than protein adducts derived from acetaminophen (Rashed et al. 1990). Proteomic analyses have revealed that, although many of the same mouse liver proteins are modified covalently by metabolites of the two compounds in vivo, that acetaminophen selectively forms adducts with various mitochondrial proteins (Myers et al. 1995). Furthermore, treatment of mice with acetaminophen, but not AMAP, induces expression of the heat shock proteins hsp25 and hsp70 (Salminen et al. 1997) and causes differential changes in expression of numerous genes associated with stress response, cell cycle, growth inhibition, cell death, cell structure, cell signalling and inflammation (Priyadarsiny et al. 2008).

Research undertaken in vitro using precision cut liver slices from various species (Hadi et al. 2012) has now indicated that our current understanding of the differential toxicity of acetaminophen and AMAP is incomplete and will need to be re-evaluated. Liver slices from mice exhibited marked liver injury when incubated with acetaminophen, which was accompanied by extensive metabolism of the drug and by glutathione conjugate formation (demonstrating that metabolic bioactivation had occurred), while mouse liver slices that were incubated with equivalent doses of AMAP exhibited a markedly reduced extent of injury and did not generate detectable levels of glutathione conjugates. These findings are entirely consistent with data obtained by other investigators in vivo in the 
Fig. 1 Role of metabolic bioactivation in liver injury caused by acetaminophen

\section{Acetaminophen}

(N-acetyl-para-aminophenol)<smiles>CC(=O)Nc1ccc(O)cc1</smiles>
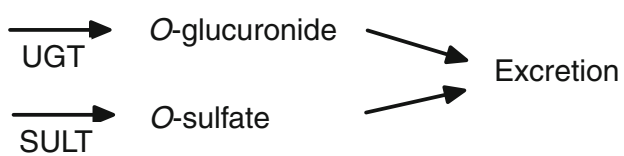

$\mathrm{N}$-acetyl-parabenzoquinoneimine (NAPQI) reactive intermediate<smiles>[Te][Te][TeH]</smiles><smiles>CC(=O)NC1C=CC(=O)C=C1</smiles>

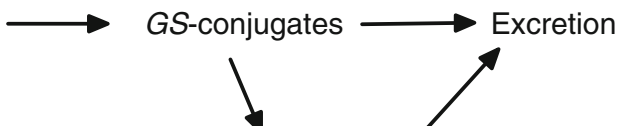

Cysteine and N-acetyl cysteine conjugates

Glutathione depletion

Covalent binding to proteins

ROs generation and oxidative stress

Mitochondrial dysfucntion

Nuclear DNA fragmentation

Inflammatory cytokine release

Inflammatory cell activation

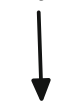

Hepatocellular necrosis

mouse and in vitro using isolated mouse hepatocytes (Rashed et al. 1990; Holme et al. 1991). In contrast, more severe toxicity was observed when rat or human liver slices were incubated with AMAP than when mouse liver slices were incubated with the compound, or when rat and human liver slices were incubated with acetaminophen. Metabolic profiling studies did not reveal an obvious metabolic explanation for the results, although markedly lower levels of one of hydroxylated metabolites (3-hydroxyacetyl-paraaminophenol; 3-OH-APAP) were evident in media from rat and human liver slices which had been incubated with the AMAP than in media from AMAP exposed mouse liver slices.

These data have highlighted a number of key data and knowledge gaps, which hopefully will be addressed in the future. It is clear that comparative in vivo metabolism and toxicity studies need to be undertaken with AMAP in species other than hamster and mouse, most notably in the rat. Detailed investigations of the mechanism of AMAP toxicity to rat, human, and mouse liver slices are also required. At present, it is not known whether the enhanced toxicity evident in rat and human liver slices when compared to mouse liver slices can be attributed to a species difference in formation of reactive intermediates, detoxification of these metabolites and/or to other considerations. In addition, it needs to be established whether the differential toxicity observed in liver slices can be reproduced using isolated hepatocytes, or in other in vitro models. One wonders whether precision cut liver slices have provided unique toxicological insights, or whether cross-species hepatocyte toxicity studies would have provided equally informative data had they been undertaken.

As Hadi et al. have noted, conventional safety studies undertaken in animals provide only limited prediction of liver injury that may be caused by new investigational drugs in humans (Olson et al. 2000). Therefore, there remains a major unmet need for alternative model systems, which are more relevant to humans and which can provide 


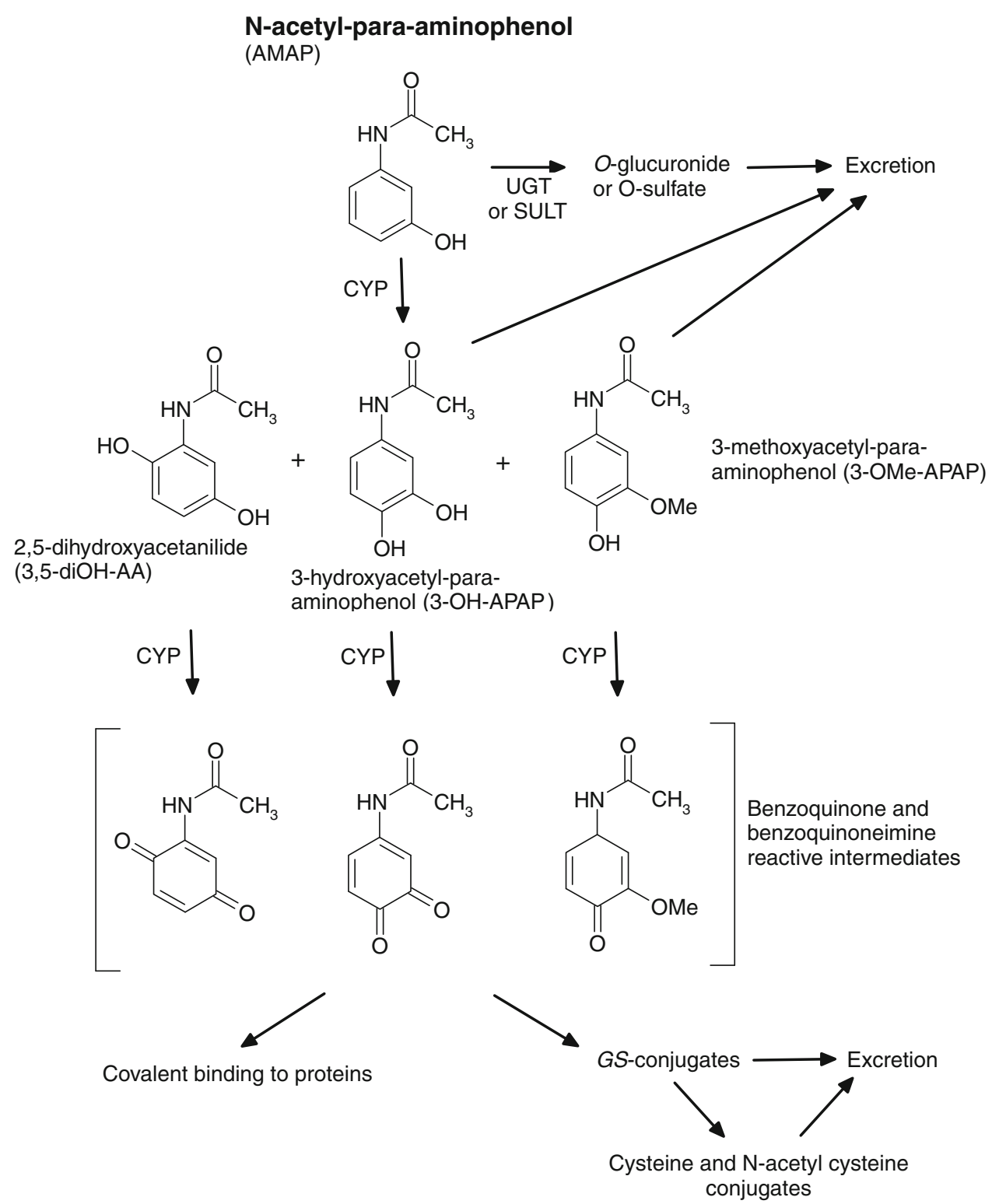

Fig. 2 Metabolism of AMAP

improved prediction of risk of liver injury in humans. It is becoming increasingly evident that metabolic bioactivation is one of several key initiating mechanisms by which numerous drugs other than acetaminophen can cause liver injury (Thompson et al. 2012) and that our ability to explore this experimentally is restricted by the limited metabolic capability and poor relevance to humans in vivo of many currently available in vitro toxicological models (Park et al. 2011). Therefore, models which are metabolically competent and can be used to profile metabolism alongside toxicity can be expected to be of particular value. The data reported by Hadi et al. have emphasized the variety and quality of data that can be obtained from precision cut liver slices, which suggests that they may merit more widespread usage.

Conflict of interest The author declares that he has no conflict of interest.

\section{References}

Hadi M, Dragovic S, van Swelm R, Herpers B, van de Water B, Russel FGM, Commandeur JNM, Groothuis GMM (2012) AMAP, the alleged non-toxic isomer of acetaminophen, is toxic in rat and human liver. Arch Toxicol. doi:10.1007/s00204012-0924-1 
Hinson JA, Roberts DW, James LP (2010) Mechanisms of acetaminophen-induced liver necrosis. Handb Exp Pharmacol 196:369405

Holme JA, Hongslo JK, Bjørge C, Nelson SD (1991) Comparative cytotoxic effects of acetaminophen ( $N$-acetyl-p-aminophenol), a non-hepatotoxic regioisomer acetyl- $m$-aminophenol and their postulated reactive hydroquinone and quinone metabolites in monolayer cultures of mouse hepatocytes. Biochem Pharmacol 42(5):1137-1142

Myers TG, Dietz EC, Anderson NL, Khairallah EA, Cohen SD, Nelson SD (1995) A comparative study of mouse liver proteins arylated by reactive metabolites of acetaminophen and its nonhepatotoxic regioisomer, $3^{\prime}$-hydroxyacetanilide. Chem Res Toxicol 8(3):403-413

Olson H, Betton G, Robinson D, Thomas K, Monro A, Kolaja G, Lilly P, Sanders J, Sipes G, Bracken W, Dorato M, Van Deun K, Smith P, Berger B, Heller A (2000) Concordance of the toxicity of pharmaceuticals in humans and in animals. Regul Toxicol Pharmacol 32(1):56-67

Park BK, Boobis A, Clarke S, Goldring CE, Jones D, Kenna JG, Lambert C, Laverty HG, Naisbitt DJ, Nelson S, Nicoll-Griffith DA, Obach RS, Routledge P, Smith DA, Tweedie DJ, Vermeulen N, Williams DP, Wilson ID, Baillie TA (2011) Managing the challenge of chemically reactive metabolites in drug development. Nat Rev Drug Discov 10(4):292-306

Priyadarsiny P, Khattar SK, Malik R, Udupa V, Seshaiah A, Rahman S, Shingatgeri VM, Bora RS, Saini KS (2008) Differential gene expression analysis of a known hepatotoxin, $N$-acetyl- $p$-amino- phenol (APAP) as compared to its non-toxic analog, $N$-acetyl$m$-amino-phenol (AMAP) in mouse liver. J Toxicol Sci 33(2): 163-173

Rashed MS, Nelson SD (1989) Characterization of glutathione conjugates of reactive metabolites of $3^{\prime}$-hydroxyacetanilide, a nonhepatotoxic positional isomer of acetaminophen. Chem Res Toxicol 2(1):41-45

Rashed MS, Myers TG, Nelson SD (1990) Hepatic protein arylation, glutathione depletion, and metabolite profiles of acetaminophen and a non-hepatotoxic regioisomer, $3^{\prime}$-hydroxyacetanilide, in the mouse. Drug Metab Dispos 18(5):765-770

Roberts SA, Price VF, Jollow DJ (1990) Acetaminophen structuretoxicity studies: in vivo covalent binding of a nonhepatotoxic analog, 3-hydroxyacetanilide. Toxicol Appl Pharmacol 105(2): 195-208

Salminen WF Jr, Voellmy R, Roberts SM (1997) Differential heat shock protein induction by acetaminophen and a nonhepatotoxic regioisomer, 3'-hydroxyacetanilide, in mouse liver. J Pharmacol Exp Ther 282(3):1533-1540

Thompson RA, Isin EM, Li Y, Weidolf L, Page K, Wilson I, Swallow S, Middleton B, Stahl S, Foster AJ, Dolgos H, Weaver R, Kenna JG (2012) In vitro approach to assess the potential for risk of idiosyncratic adverse reactions caused by candidate drugs. Chem Res Toxicol 25(8):1616-1632

Tirmenstein MA, Nelson SD (1989) Subcellular binding and effects on calcium homeostasis produced by acetaminophen and a nonhepatotoxic regioisomer, 3'-hydroxyacetanilide, in mouse liver. J Biol Chem 264(17):9814-9819 